\title{
Research on the Feedback Teaching and Interactive Thinking and the Applications on Command Information System Teaching
}

\author{
Zhaoxiang He, Ming Yang \\ Border Defence Academy of PLA, Xi'an City, Shaanxi Province, 710108, China.
}

Keywords: Feedback Teaching, Interactive Thinking, Command Information System, Applications.

\begin{abstract}
This paper conducts research on the feedback teaching and the interactive thinking and the applications on the command information system teaching. Modern command information system requirements description framework from the military on the contents of requirements development specification requirements engineering technology application, and the training of the students will be the key point for the further development of the military power. Informatization is now characterized by system against war, under the condition of the weapon equipment system more perfect that gains the information advantage. This paper integrate the feedback teaching and the interactive thinking to design the new education and training schedule for command information system teaching that will optimize the training steps and enhance the performance that is beneficial.
\end{abstract}

\section{Introduction}

Information management and general information systems professional major is to cultivate moral, intellectual, physical all-round development, has a solid theoretical basis for economic management and computer, meet the needs of the socialist market economy and the modernization, in government departments, research institutes and enterprises and institutions of management departments engaged in information management and information system design and development of applied talents.

Information management and information system specialty is the new, comprehensive, cross of the discipline the discipline foundation consists of three parts: the modern management science, modern information science and information technology, modern system science and system engineering. As we can see, it is the original MIS discipline concept further expansion. The cultivation of the major graduates should be able to undertake all kinds of the information management at all levels of work, engaged in various types of information system construction and management. However, as for the ordinary training, there are still some challenges. (1) The schools of the fuse professional in computer related courses and even in the whole that have very big difference on the professional curriculum. (2) Due to different industries, different companies and different position of fuse professional student knowledge structure has different characteristic demand, so under the unified system of professional, should be further subdivided into different professional direction to meet the needs of more specific. (3) Traditional way of the experiment are topics designated by the teacher, students complete studies or systems development, in the process of middle school students and didn't have a chance to contact the real environment that will be the primary challenge for the education procedures [1-2].

For information-based war, both sides attack first goal is to link the country's political, economic, the military and the society as a whole "central nervous," information system. If one party control or destroy each other in the war of information system, information mastered absolute advantage, it also have the initiative and the right of winning on the battlefield and to establish and perfect the disaster recovery mechanism, it is to master the basic guarantee of the information superiority that has its existence, information systems can calmly deal with all kinds of disaster and blow. Therefore, the education of command information system teaching is becoming urgent and necessary.

Teaching process is not a simple sense of the teachers and the students' bilateral activity process, but a complex interaction between teachers and students activities. The process of interaction between teachers and students that is mainly refers to the teachers and students in teaching and an interactive process between students and the students. Therefore, the teaching feedback is influence the teaching effect of important means and the conditions. The teaching feedback should be run 
through the whole process of teaching. It is not complete without the teaching feedback, teaching, and the lack of an effective teaching feedback that is impossible to have success in teaching. In the following sections, we will discuss the corresponding challenges and countermeasures in detail.

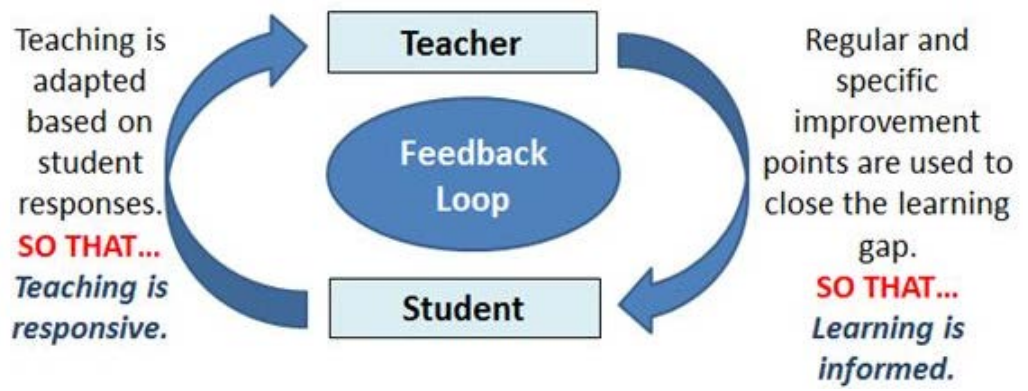

Fig. 1 The Feedback Teaching and Interactive Thinking Demonstration

\section{The Proposed Methodology}

Command Information System Principles. Modern command information system requirements description framework from the military on the contents of requirements development specification requirements engineering technology application in the command information system requirements development that based on features of the level of the demand that will command information system requirements are divided into two levels: the military demand and the system requirements. Military requirements are military personnel, military operations of command information system of military mission, a description of the tasks and activities, as well as the ability requirements associated with these activities, information interaction requirements, operation or operation requirements and other requirements, constraints, etc. Informatization is now characterized by system against war, under the condition of the weapon equipment system more perfect, information advantage, the more obvious, and the more likely they are to convert this advantage to decisions and the actions, so as to gain the initiative in the war. The features of the command information system can be listed below.

$>$ In informationization combat troops in the field of knowledge should have the ability to share the battlefield situational awareness, and on the common understanding commander intention ability, and coordination and the ability of self-synchronous operations [3].

$>$ Information combat, command departments according to the functions as the main set, while therefore and form the relatively independent modules, such as basic intelligence, information gathering process function module, information transmission function modules, operational management, decision-making, planning, organization, operational supervision, control and coordination function modules, operational functions of the various security module, etc.

$>$ In the information technology as the core of the new military revolution the army is essentially take longitudinal tree command system to implement operation command.

$>$ In order to improve the survival ability, the command system and its internal subsystems, the command of the subject must adapt to the constantly changing environment while including the collaboration and coordination between the friends, as well as the enemy, the biggest comprehensive efficiency to play their own command system.

The Interactive Thinking and Teaching. "Interactive" teaching mainly refers to the core school education teaching process, dominated by faculty and students as the main body participation, based on the students learning interest and internal needs is characterized by students actively participate in teaching, in order to realize the overall development of the students' ability of the main body for the purpose of teaching form. It is no longer limited to traditional unidirectional and general bidirectional activities, but stressed that teaching is a kind of multilateral activities, students and teaching objects, students and students, faculty and multilateral interaction between students and the faculty.

Interactive teaching mode is a kind of take the student as the main body, teacher as the leading factor, based on cultivating students' innovation ability, improve teacher's professional level of a kind of brand-new teaching mode that is to adapt the development of the contemporary social and cultural ideological trend and the needs of the education teaching reform a new teaching mode. It requires that 
the classroom teaching is a two-way interaction between teachers and students practice, is a mutual exchanges and cooperation between teachers and students, inspire each other, and improve process.

Interactive teaching method put forward higher requirements for teachers as that need not only has the wide range of basic professional knowledge but also has a rich experience in professional practice. Therefore, teachers in the theoretical study on at the same time, still need to society, to participate in the professional practice to enrich myself in practice, and make the book theory to accept the test of practice. The application of the interactive teaching mode can change this phenomenon, so that the students really involved in the teaching process, arouse their curiosity to improve the learning interest and fully exert their innovation ability and logical thinking ability as shown below [4].

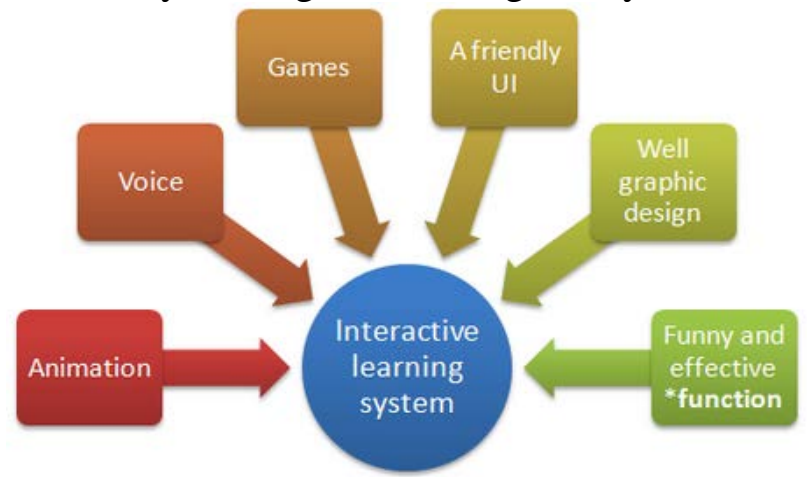

Fig. 2 The Interactive Learning Systematic Architecture

Feedback Teaching Concept. From the perspective of management, feedback is refers to the information about the actual level and the gap between the reference level, this information is used to change behavior. From the pedagogy angle of view to analysis that is mainly refers to the teachers' teaching feedback on students' learning performance and the gap between the teaching goals gives effective information, students can use the information to confirm, increase, shift or even reconstruct their own knowledge, effective feedback can help the students to close the gap, to achieve the learning goals. The teaching feedback plays a very important role in the teaching process and in the teaching process, teachers and students are constantly output information, and absorb information, meanwhile constantly feedback. Teachers understand students' learning from feedback situation while adjust the teaching program that students know yourself from the feedback information of the development of the knowledge and the ability to find and correct errors based on the listed aspects.

$>$ Related activities in the teaching practice, in general, the main body of whether to use the feedback to improve their teaching and learning behavior, make the teaching and learning in a positive and effective state, to ensure that through making full use of the effective feedback information to produce satisfactory teaching effect.

$>$ Teachers and students both sides of the sensitive sensitivity is an effective teaching feedback must have the basic conditions. Due to the teaching feedback is mainly achieved by means of visual and auditory activity, therefore teaching teachers both sides should have good visual and sensitivity that will largely promote the further development of the issues.

$>$ Sensitive sensibility, to a large extent depends on the sharpness, the receptor and sharpness is that this kind of sensor is sensitive to reflect both inside and outside all sorts of information provides a good condition and environment.

Teaching Efficiency Enhancement. Teaching efficiency consciousness is a kind of the composite structure of teachers of higher cognitive activity is refers to the teachers in the teaching process of the teaching efficiency of a cognitive and detection as is expected and directivity of the teaching effect of the regulation consciousness. Teaching efficiency is affected by many factors, but the teaching body is the most active and decisive role in a number of important factors. Teaching the main structure of each part and its internal conditions directly affects the teaching efficiency and the extension of the teaching body structure has been widely, it includes the teacher students hierarchy, hierarchy, gender structure, sex structure, age structure, teachers students age structure, class structure, the structure of the class teacher amount and ratio of the raw division. Therefore, the teaching efficiency and teaching efficiency is directly related to the consciousness, the consciousness 
of teachers' teaching efficiency effectively restricts efficiency of classroom teaching. At the same time, teacher's effective teaching behavior is a reflection of its consciousness of teaching efficiency, and proportional to stronger the sense of teaching efficiency, the more effective teaching behavior, teaching effect is diverse.

The Information System Teaching Suggestions. Given the characteristics of the current social needs fuse professional should raise have theory foundation of basic skills and strong professional ability of graduates, and therefore fuses the connotation of professional or subject how to positioning, how to determine the direction of the personnel training, how to build the ability oriented curriculum system and so on all is an important problem worthy of study. Correspondingly, we propose related suggestions as follows. (1) Curriculum system is to help students build the premise condition of the complete knowledge structure, how to straighten out the professional curriculum system is the key to improve the level of computer education problem. (2) For fuse professional students, it must have by means of computer technology, the advanced management idea into practice. (3) Fuse professional training is foundation of modern management science has a solid theoretical knowledge, mastering modern information technology and the system engineering method of comprehensive and practical talents. This is just a big training objectives, the specific needs of different working environment for talents is different. (4) According to fuse professional training objective, corresponding theoretical system shall be divided into computer culture knowledge, basic knowledge of computer technology, basic knowledge of information management, information system application and so on four levels.

\section{Conclusion}

In this paper, we conduct basic analysis on the feedback teaching and the interactive thinking and the applications on the command information system teaching. In the early days, command information system is the typical pattern is operating system development a website, which contains a number of products and services, the system of one terminal server through network connection to a customer service, the resulting data system is unique, form a single closed loop. But today, this model has been difficult to cope with needs of the development of the command information system how to realize the integration and data sharing between different systems and the value of mining is a real challenge. Our paper integrates the feedback teaching and the interactive thinking to propose novel perspective of the command information system teaching paradigm that will be meaningful.

\section{References}

[1] Pollpeter, Kevin, et al. "Enabling Information-Based System of System Operations: The Research, Development, and Acquisition Process for the Integrated Command Platform." SITC Policy Briefs 2014.9 (2014).

[2] Yang, Su Min, et al. "A New Improved Attribute Weight Algorithm Based on Rough Sets Theory for One Command Information System." Advanced Materials Research. Vol. 989. 2014.

[3] Yoo, Donghee, Sungchun No, and Minyoung Ra. "A Practical Military Ontology Construction for the Intelligent Army Tactical Command Information System." International Journal of Computers Communications \& Control 9.1 (2014): 93-100.

[4] ZHAO, Fei, and Jun-jie LIU. "Application of Cloud Computing in Construction of Command Information System [J]." Communications Technology 4 (2012): 002. 